\title{
Wheelchair Wheel Device
}

National Cancer Institute

\section{Source}

National Cancer Institute. Wheelchair Wheel Device. NCI Thesaurus. Code C51068.

A wheel designed to be used on a wheelchair. 